\title{
DERECHO DEL TRABAJO Y COERCIBILIDAD PENAL
}

Mário Garmêndia Arigón ${ }^{1}$

\section{RESUMEN}

En Uruguay, la aprobación de la № 19.196 (del 25 de marzo de 2014) generó un fuerte debate sobre la pertinencia del Derecho Penal del Trabajo. La coercibilidad de las normas laborales es un elemento de indiscutible importancia a la hora de garantizar la eficacia de aquellos preceptos jurídicos. Sin embargo, no todos coinciden en que la penalización de los incumplimientos sea el mecanismo adecuado para conseguir el objetivo perseguido.

PALABRAS CLAVES: Derecho Penal del Trabajo - coercibilidad de las normas eficacia de las normas laborales

\section{INTRODUCCIÓN}

Con la promulgación en Uruguay de la ley № 19.196, del 25 de marzo de 2014, finalizó una etapa de intensas polémicas en torno a una norma que consagra un delito penal direccionado hacia el empleador (o empresario) que no adoptare los medios de resguardo y seguridad laboral previstos en la ley y su reglamentación de forma que ponga en peligro grave y concreto la vida, la salud o la integridad física del trabajador. A partir de ahora y con la norma ya vigente, se abren nuevos debates, algunos de los cuales, según se ha anunciado, incluso pondrán foco en la adecuación o no de aquélla al texto constitucional.

El presente aporte no tiene por finalidad enfocar el estudio particular del texto de la nueva norma legal uruguaya, sino que, tomando a ésta como pretexto, se propone realizar algunos comentarios generales acerca del empleo de la herramienta del Derecho penal como mecanismo para asegurar el acatamiento de los preceptos del Derecho laboral.

\footnotetext{
${ }^{1}$ Doutor e mestre Docente de DTSS en la Universidad de la República (Montevideo, Uruguay) e no Centro Latinoamericano de Economía Humana - CLAEH em Punta del Leste. Doutor em Direito Social pela Universidade Castilla-La Mancha, na Espanha. Mestre en DTSS (Universidad de la República - Uruguay)
} 


\section{II- SOBRE LA COERCIBILIDAD DE LAS NORMAS JURÍDICAS EN GENERAL Y DE LAS NORMAS LABORALES EN PARTICULAR}

Se ha señalado que la estabilidad de los ordenamientos jurídicos depende en buena medida de que las normas que los integran, reciban y proyecten adecuadamente los valores que socialmente son estimados como relevantes1. A mayor coincidencia entre aquellas normas y estos valores, mayor debería ser la disposición de los individuos hacia el acatamiento espontáneo y natural de las primeras.

Pero es evidente que ningún ordenamiento puede confiar en que sus normas se sostendrán exclusivamente en la adhesión social que sean capaces de suscitar. Primero, porque no todos los sujetos comparten los mismos valores. Segundo, porque los que sí lo hacen, pueden -y suelen- disentir en cuanto a la relevancia o jerarquía que les reconocen a cada uno de ellos. Y tercero, porque ni siquiera se puede dar por entendido que todos los individuos se comportarán según sus propias convicciones personales, ya que no es infrecuente que muchos lo hagan alentados por impulsos de otro tipo, como el simple interés egoísta2.

Por eso se hace imprescindible que los preceptos jurídicos vayan acompañados de un mecanismo que les permita sortear la resistencia de quienes deberían acatarlos3. Se trata de la coercibilidad, que algunos juristas han destacado como el elemento verdaderamente definidor de las normas jurídicas4. A través de la misma, el Derecho amenaza con una sanción para que el destinatario de la norma se sienta inclinado a cumplirla, incluso cuando de ello no resulten satisfechos sus intereses o sus convicciones. La norma jurídica procura despertar en el individuo un interés real en respetarla: debe hacerlo para evitar que sobre él recaiga una consecuencia no deseada.

Se ha dicho, por esta razón, que el impulso hacia el acatamiento de las normas a veces se reduce a un simple cálculo, que pasa por comparar las ventajas

\footnotetext{
1.- Kelsen, H., Teoría pura del Derecho, Eudeba, Bs. As., 1960, p. 142. Carnelutti, Francisco, Teoría General del Derecho, Ed. Revista de Derecho Privado, Madrid, 1941, p. 54.

2.- Nino, Carlos, Introducción al análisis del derecho, $2^{\mathrm{a}}$ ed. ampliada y revisada, $12^{\mathrm{a}}$ reimpresión, Ed. Astrea, Bs. As., 2003, p. 4.

3.- $\quad$ Carnelutti, F., op cit., p. 62.

4.- Kelsen, H., Teoría, cit., p. 81 y también: Validez y eficacia del derecho, Ed. Astrea, Bs. As., 2005 , p. 50 y 51.
} 
de cumplir con los beneficios de no hacerlo. Cuando el resultado de esa comparación conduce al sujeto a observar una norma que no es satisfactoria de su interés (pero que prefiere acatar para no recibir el perjuicio que generaría la opción de no cumplir), se produce lo que Carnelutti llamó la "composición económica del conflicto"5. En este caso, para que la amenaza sea capaz de despertar ese interés, su magnitud debe ser mayor a la recompensa que podría resultar de la desobediencia del precepto. De lo contrario, si el atractivo de no cumplir sigue siendo superior a la aflicción que provoca la amenaza de la sanción, el estímulo no existirá6.

Ahora bien, también parece bastante claro que no todas las normas jurídicas son capaces de despertar la misma vocación de acatamiento espontáneo y que, consecuentemente, algunas de ellas necesitan ser acompañadas de un mayor énfasis de coercibilidad. En alguna ocasión7 ilustramos esta idea comparando el artículo 256 del Código Civil uruguayo8 con las normas que imponen a los contribuyentes la obligación de pagar tributos. El ejemplo es interesante porque permite apreciar la distancia que existe entre una y otras en cuanto a las motivaciones que pueden determinar el acatamiento por parte de sus destinatarios. $\mathrm{Y}$, por lo tanto, también permite comprender la diferente intensidad de coercibilidad que será necesario que acompañe a unas y otras a los efectos de asegurar su cumplimiento.

Por múltiples razones9, las normas laborales no se encuentran entre aquellas cuyo cumplimiento pueda confiarse a la mera espontaneidad de los sujetos a quienes están dirigidas. Esta característica se hizo patente desde muy temprano, pues afectó severamente a la legislación industrial que en las primeras décadas del siglo XIX comenzó a ser adoptada por algunos Estados europeos. Muchas de esas normas -la mayoría de las cuales apuntaba a limitar el trabajo de los niñosterminaron sufriendo una suerte de derogación por la vía de los hechos, pues

\footnotetext{
5.- $\quad$ Carnelutti, F., op. cit., p. 52.

6.- $\quad$ Carnelutti, F., p. 64.

7.- $\quad$ Eficacia práctica de las normas laborales. Entre el Derecho y la realidad, FCU, 2005, p. 27 y ss.

8.- $\quad$ Código Civil, art. 256: "Los hijos, cualquiera que sea su estado, edad y condición, deben honrar y respetar a su padre y a su madre". La norma es muy similar a la consagrada en el primer inciso del artículo 222 del Código Civil chileno ("Los hijos deben respeto y obediencia a sus padres") y en el artículo 454 del Código Civil peruano ("Los hijos están obligados a obedecer, respetar y honrar a sus padres"). Disposiciones similares están consagradas, por ejemplo, en los Códigos Civiles de Argentina, Brasil, Colombia, Ecuador, El Salvador, España, Italia y otros países.

9.- $\quad$ Vide, del autor: Eficacia práctica de las normas laborales, cit., p. 35 y ss.
} 
resultaron completamente obviadas por los empleadores, que solo las veían como un elemento que obstruía la consecución del objetivo excluyente de alcanzar el éxito económico10.

Por este motivo rápidamente se advirtió que la norma laboral que pretendiera contar con alguna chance de ser aplicada en la práctica, debía ir acompañada de un sistema que se asegurara de controlar su cumplimiento. $Y$ fue así que una ley inglesa de 1833 (la denominada Factory Act) creó el primer cuerpo de inspectores de trabajo (inspectorate of factories)11; instrumento que fue introducido en Uruguay a través de la ley № 5.350, del 17 de noviembre de 1915, conocida como la ley de las 8 horas, que así parece haber sido la primera que demostró verdadera vocación de ser efectivamente aplicada a la realidad práctica12.

De todos modos, es frecuente que incluso hasta la actualidad se continúe señalando el déficit de efectividad que suele afectar a las normas laborales, fenómeno que, sin ser exclusivamente latinoamericano13, se aprecia con singular intensidad en estas latitudes 14.

Por estas razones resulta evidente que las normas laborales necesariamente deben ir acompañadas de mecanismos de control de su cumplimiento y que, en definitiva, aquella que no cuente con adecuados instrumentos de constricción, padecerá un defecto que muy probablemente condicionará su viabilidad15. Las normas laborales -se ha señalado- por su propio carácter requieren un sistema reforzado de sanciones para prevenir su ineficacia16.

10.- Olszak, N., Histoire du Droit du Travail, Histoire du Droit du Travail, ed. Económica, París, 2011, p. 52.

Vide http://www.parliament.uk/about/livingheritage/transformingsociety/livinglearning/19thcentury. Durand, Paul y Jaussaud, R., Traité de Droit du Travail, T. I, Dalloz, París, 1947, p. 75 ; Pérez Botija, Eduardo, Curso de Derecho del Trabajo, 6ª ed., Tecnos, Madrid, 1960, p. 61.

12.- $\quad$ Barbagelata, Héctor-Hugo, El Derecho del Trabajo en América Latina, MTySS, Madrid, 1985, p. 55

13.- $\quad$ Cfe. Blanc-Jouvan, N., II caso francese in Lavoro e Diritto, año I, No 3, VII, 1987, p. 543, cit. por Barbagelata, Héctor-Hugo, El particularismo del Derecho del Trabajo y los Derechos Humanos Laborales, FCU, Mdeo., 2009, p. 119.

14.- $\quad$ Plá Rodríguez, Américo, "El Derecho del Trabajo en América Latina. Sus crisis y sus perspectivas", in rev. Derecho Laboral, T. XXI, No 110, abril-junio 1978, p. 139; Ermida Uriarte, Óscar, Las relaciones de trabajo en América Latina, Colección Crítica \& Comunicación, № 2, OIT, Lima, 1991, p. 9; Deveali, Mario L., in La integración del Derecho del Trabajo, publ. de ILADTSS, Santa Fe, 1969, p. 71, cit. por Barbagelata, $\mathrm{H}-\mathrm{H}$, El Derecho del Trabajo en América Latina, cit., p. 45; De la Cueva, Mario, El Nuevo Derecho mexicano del Trabajo, 19ae edición, tomo I, Ed. Porrúa, México, 2003, p. 540.

15.- Barbagelata, $\mathrm{H}-\mathrm{H}$, Derecho del Trabajo, t. I, vol. 2, 3a ed. actualizada con la colaboración de Daniel Rivas, FCU, Mdeo., 2007, p. 10-11.

16.- $\quad$ Desdentado Bonete, Aurelio, Prólogo a la obra de Baylos Grau, Antonio y Terradillos, Juan, Derecho Penal del Trabajo, Ed. Trotta, Madrid, 1990, p. 8. 


\section{III- CONTROL DIRECTO Y CONTROL INDIRECTO DE LAS NORMAS LABORALES}

Los ordenamientos jurídicos laborales han ido incorporando a lo largo de la historia diversos instrumentos tendientes a provocar (o forzar) la eficacia práctica de sus normas. El elenco es muy variado e incluye algunos mecanismos que no tienen parangón en otras disciplinas jurídicas, como notoriamente lo son los denominados "medios de autotutela", en los cuales la "coercibilidad" proviene de los propios interesados en la aplicación de la norma.

En el plano de la "heterotutela" (mecanismos de origen estatal), las normas laborales buscan preservar su eficacia a través de múltiples medios. Algunos de ellos apuntan explícitamente a la vigilancia y control del acatamiento de las normas laborales y, en caso de infracción, determinan la imposición de una sanción.

Los mecanismos de este tipo (llamados "directos"17) responden a una concepción básica del funcionamiento del sistema jurídico: el cumplimiento de la norma debe ser vigilado o controlado por la autoridad y, correlativamente, la infracción de aquélla debe ser sancionado por la autoridad legitimada a tales efectos.

Otros mecanismos persiguen el mismo objetivo a través de fórmulas más sutiles o indirectas, que inducen a cumplir voluntariamente, haciendo más gravosa la opción del incumplimiento (p. ej.: a través de la imposición de recargos, intereses, multas o penalizaciones similares en caso de no pago en fecha de un determinado crédito) o que facilitan o hacen más expeditivo el accionamiento judicial al trabajador.

\section{IV- DERECHO PENAL Y LEGISLACIÓN DEL TRABAJO}

Lo que se ha dado en llamar Derecho Penal del Trabajo se ubica dentro de los mecanismos de control de cumplimiento que hemos llamado "directos" (control / sanción).

17.- $\quad$ Del autor: Eficacia práctica de las normas laborales, cit., p. 59 y ss. 
Lo primero que se debe señalar, tiene que ver con la ambivalente relación histórica que han mantenido el Derecho del Trabajo y el Derecho Penal18. Es difícil encontrar alguna otra disciplina jurídica cuyos institutos fundamentales hayan merecido un tratamiento tan variable de parte del Derecho Penal.

Empezando con la constatación de que, según ha señalado la doctrina, las relaciones laborales nacieron en el seno del Derecho Penal19. Ésa fue la primera ubicación que se destinó a las manifestaciones colectivas del movimiento obrero y que prevaleció en los ordenamientos jurídicos durante prácticamente todo el siglo XIX20. Pero las mismas conductas que hace poco más de un siglo eran tipificadas como ilícitos penales, son en la actualidad merecedoras de la más elevada protección y promoción.

Es en estas circunstancias que, paradojalmente, el Derecho Penal vuelve a asumir un papel en relación a las normas laborales. Aunque ahora el mismo se encuentra, en cierta forma, en las antípodas del que tuviera hace poco más de un siglo, pues consiste en sancionar el incumplimiento de estas últimas21.

En el caso del ordenamiento jurídico uruguayo, con anterioridad a la promulgación de la ley 19.196, sólo existía alguna disposición aislada específicamente dirigida a sancionar penalmente la infracción de normas laborales. La referencia, más bien indirecta ( $y$, sobre todo, bastante olvidada), se detecta en la ley 5.427, del 29 de mayo de 1916. Esta ley consagró algunas disposiciones con la finalidad de "Hacer efectivas las penas que establecen los artículos $9^{\circ}$ de la ley de 21 de Julio de 1914 [se refiere a la ley 5.032, sobre prevención de accidentes de trabajo] y $6^{\circ}$ de la ley de 17 de Noviembre de 1915 [se refiere a la ley 5.350]...".

La norma estableció un procedimiento administrativo que podía derivar hacia la sede jurisdiccional en caso que el infractor no diera cumplimiento al pago de la multa a su cargo.

En el art. 8 de la ley se establecía lo siguiente: "Consentida la sentencia de primera instancia, si no se efectuase el pago de la multa en el acto de la notificación

\footnotetext{
18.- $\quad$ De Buen, Néstor, Derecho del Trabajo, T. I, 17ª̣ ed., Ed. Porrúa, México, 2005, p. 127.

19.- $\quad$ Baylos, A. y Terradillos, J., op. cit., p. 15.

20.- $\quad$ El proceso de despenalización se produjo en momentos diferentes según cada país. En Gran Bretaña se reconoció la libertad de asociación en 1824, en Francia, se derogaron en 1884 las normas penales que sancionaban la formación de sindicatos y las huelgas (los delitos habían sido tipificados en el Código Penal de 1810, arts. 414 a 416), mientras que en Alemania, algunos Estados levantaron las prohibiciones entre 1841 y 1859 , pero no fue sino hasta 1872 que una ley del recién unificado imperio generalizó las libertades. Cfe. De la Cueva, M, op. cit., p. 17.
}

21.- $\quad$ Baylos, A. y Terradillos, J., op. cit., p. 34. 
o dentro del tercero día, deberá decretarse el arresto sustitutivo, de acuerdo con lo establecido en el artículo 396 del Código de Instrucción Criminal. Lo mismo se hará en el caso en que, notificado el cúmplase de la sentencia, no se hubiere efectuado el pago de la multa dentro del tercero día".

En el artículo siguiente se aclaraba que cuando la infracción hubiese sido cometida por una persona jurídica, el juicio sería seguido “...con el representante o gerente que tenga a su cargo la dirección del trabajo y en el cual se hará efectiva la pena".

Al realizar una evaluación crítica de los progresos verificados en la legislación laboral hasta mediados de la década de 1960, Barbagelata detectaba algunos defectos en el funcionamiento del Instituto Nacional del Trabajo, entre los cuales hacía referencia al "...retaceo de la aplicación de los procedimientos expeditivos de la ley de 1916"22.

En cambio, en el Derecho de otros países el empleo de este tipo de mecanismos de constricción penal es bastante frecuente23 y están inspirados en la preocupación por definir instrumentos aptos para dotar a estas últimas de vigencia real24.

\section{V- OBJECIONES AL DERECHO PENAL DEL TRABAJO}

El Derecho Penal del Trabajo recibe cuestionamientos de diversa inspiración. Por una parte, ha sido duramente objetado, naturalmente, por las corrientes que pugnan por la flexibilización del Derecho del Trabajo. Desde dicha perspectiva, la intervención penal aparece como un elemento de rigidez extrema y, en consecuencia, se le impugna porque se le atribuye la característica de resultar severamente perjudicial e inoportuna, dado que tiende a quitar incentivos para la

\footnotetext{
22.- $\quad$ Manual, cit., p. 30.

23.- $\quad$ Cfe. Baylos, A. y Terradillos, J., op. cit., p. 31 y Narvaez Bermejo, Miguel A., Delitos contra los derechos de los trabajadores y la Seguridad Social, Tirant lo Blanch, colección laboral, 60, Valencia, 1997, p. 13.

24.- $\quad$ Baylos, A. y Terradillos, J., op. cit., p. 17; Vida Soria, José; Monereo Pérez, José Luis y Molina Navarrete, Cristóbal, Manual de Derecho del Trabajo, 7aa ed., Ed. Comares, Granada 2009, p. 715. Pera, Giuseppe, Diritto del Lavoro, 5a ed., Cedam, Milán, 1995, p. 607 y ss.; Ghezzi, Giorgio, Romagnoli, Umberto, II diritto sindacale, $2^{a}$ ed., Zanichelli, Bologna, 1987, p. 290; Javillier, Jean-Claude, Manuel de Droit du Travail, cit., p. 327 y 328; De Buen, N., op. cit., p. 127 y 615; Mascaro Nascimento, Amauri, Iniciação ao Direito do Trabalho, 28a ed., LTR, São Paulo, 2002, 648; Vázquez Vialard, Antonio y Navarro, Marcelo Julio, Policía del Trabajo, Ed. Astrea, Bs. As., 1990, p. 123.
} 
inversión empresarial, que se considera imprescindible para fomentar el desarrollo económico y la creación de fuentes de trabajo25.

Pero más allá de estas objeciones -previsibles cuando la cuestión se encara a partir de una mirada como la que se termina de referir- hay que decir que el Derecho Penal del Trabajo también ha sido criticado por razones de otra índole.

Dentro de ellas, por ejemplo, se encuentran aquellos puntos de vista que ponen el énfasis en la denominada "naturaleza accesoria del Derecho penal", que pasa por concebir a dicha disciplina como el "último remedio" y al que, en cuanto tal, sólo debería acudirse “...cuando las demás ramas del Derecho se revelan incapaces de brindar la debida tutela a bienes jurídicos de relevancia para la propia existencia del hombre y de la sociedad"26.

En esta línea de razonamiento, se ha sostenido que "...la ley penal no debe utilizarse cuando medidas que impliquen menos sufrimiento sean tan efectivas o casi tan efectivas para reducir la frecuencia de la conducta en cuestión"27.

La mejor doctrina penal se ha ocupado desde siempre por dejar señalado el riesgo que supone la profusión desmesurada de definiciones delictivas, fenómeno que -se ha dicho- "...tiene su causa en la manía de gobernar demasiado, y en la necedad de gobernarlo todo por medio de procesos criminales"28.

En el caso del Derecho Penal del Trabajo, es probable que el defecto se haya traducido en una frecuente inaplicación práctica de muchos tipos delictivos, siendo común encontrar comentarios que destacan su poca proyección en la realidad, al punto que ha llegado a señalarse que no es más que una convención lingüística, "mal valorada doctrinalmente, difícilmente apreciada por la interpretación jurisprudencial, ignorada por los sindicatos y utilizada parcialmente por la Administración"29.

25.- $\quad$ Baylos, A. y Terradillos, J., op. cit., p. 33.

26.- Luisi, Luizi, Os principios constitucionais penáis, Sergio Antonio Fabris Editor, Porto Alegre, 1991, p. 27, cit. por Cervini, Raúl y Adriasola, Gabriel, El Derecho Penal de la Empresa desde una visión garantista, Ed. B de F, Montevideo-Buenos Aires, 2005, p. 316.

27.- $\quad$ Cervini, R. y Adriasola, G., op. cit., p. 316. Francesco Carrara se refería al tema adhiriendo a la fórmula de Ellero (Scritti minori, p. 78, Bologna, 1875) cuando señalaba que "deben castigarse sólo aquellas acciones que violan o tienden a violar los derechos ajenos, cuando éstos no se pueden asegurar de otro modo, y la punición no implique mayor daño que la impunidad', Carrara, Francesco, Programa del Curso de Derecho Criminal, Parte General, T. I, Ed. Depalma, Bs. As., 1944, p. 38.

28.- $\quad$ Carrara, F., op. cit., p. 38.

29.- $\quad$ Baylos, A. y Terradillos, J., op. cit., p. 48. En la misma línea: Por su parte, Vida Soria, Monereo y Molina Navarrete, señalan que "...la potestad de punición tiene reservada (...) un amplio campo de actuación en materia laboral, aunque (...) hemos de lamentar una clara disociación entre la representación normativa del ordenamiento -fuerte presencia de tipos laborales en el Código [Penal] - y 
Esto ha contribuido a generar el efecto que el italiano Umberto Romagnoli ha llamado de "conciencia falsa" de este sector del ordenamiento jurídico, donde se advierte “...una separación radical entre las conductas castigadas y una realidad que las reproduce cotidianamente impunes" 30.

No es casual, entonces, que en la doctrina se haya introducido el debate acerca de la necesidad de "despenalizar selectivamente" las conductas transgresoras de preceptos laborales, transformándolas paulatinamente en objeto de otro tipo de sanciones (de carácter administrativo, por ejemplo)31, eludiendo así el riesgo de la "inflación penal" y proponiéndose la revalorización de algunas infracciones que, por su muy especial gravedad, conservan su definición como tipos penales y, de este modo -por su propio carácter excepcional- logren enfatizar adecuadamente el mensaje de aversión que las mismas provocan en la conciencia jurídica colectiva32.

\section{VI- CONCLUSIÓN}

Es oportuno destacar la importancia de evitar los abordajes simplistas de esta temática, que sin demasiadas dificultades podrían estar basados en una explicación rápida y relativamente cómoda acerca de la necesidad y el mérito del Derecho penal del trabajo33.

Algunos han visto en la alternativa criminalizadora de las infracciones laborales una forma de contribuir a crear una conciencia social contraria a las actitudes antijurídicas en el mundo del trabajo, que permite enfrentar la tendencia a la infravaloración de los perjuicios que se provocan con dichas conductas y que

su funcionamiento práctico - escasa aplicación de estos tipos penales". Vida Soria, José; Monereo Pérez, José Luis y Molina Navarrete, Cristóbal, Manual de Derecho del Trabajo, 7aㅡ ed., Ed. Comares, Granada 2009, p. 715. Además, vide: Ghezzi, Giorgio y Romagnoli, Umberto, II raporto di lavoro, t. II, Zanichelli, Bologna, 1989, p. 391.

30.- Romagnoli, U., "Illeciti in materia di lavoro e nuove prospettive sanzionatorie", in RGLPS (1977), p. 351, cit. por Baylos, A. y Terradillos, J., op. cit., p. 35. Refiriéndose a cuestiones similares, Cervini y Adriasola señalan "...la inocultable impunidad del delito hacia la empresa y desde ella" y recuerdan a Grezzi cuando señalaba que "si se dirige la mirada, no a la legislación, sino a la práctica jurisprudencial, la conclusión es notoria: no se procesa por estos delitos". Op. cit., p. 321. Baylos y Terradillos aluden a datos estadísticos que revelan que el sometimiento efectivo a la justicia penal de los infractores de las normas laborales es ínfimo en Francia, Gran Bretaña, Estados Unidos y España (Op. cit., p. 45 y 47 ).

31.- $\quad$ Ghezzi, G. y Romagnoli, U., II raporto..., cit., p. 394 y 395.

32.- $\quad$ Padovani, T., "Recenti modifiche del diritto penale del lavoro", in GDLRI (1982), p. 418, cit. por Baylos, A. y Terradillos, J., op. cit., p. 35.

33.- Baylos, A. y Terradillos, J., op. cit., p. 38. 
subraya los deberes objetivos que vinculan a los empleadores con respecto a sus trabajadores.

Se ha dicho con razón que la sanción penal de tales conductas sirve para generar el mensaje de que las conductas de este tipo, sobre todo cuando ponen en riesgo la integridad física del trabajador, sí son y deben reconocerse como graves en el marco del Estado social y democrático de Derecho34.

En cualquier caso, también resulta esencial tomar los recaudos pertinentes para no dejarse ganar por los "planteamientos moralistas abocados a la siempre inoperante huída al Derecho penal, mera coartada del legislador, tantas veces lamentada..."35.

$\mathrm{Y}$, en especial, recordar que muchas veces el Derecho penal del trabajo ha terminado por convertirse en lo que notablemente refieren Ghezzi y Romagnoli: un monumental sarcófago en el que el Estado entierra ostentosa y solemnemente la protección que debe al trabajo, pretendiendo así expiar de su conciencia el pecado de no saber hacer frente a su verdadera obligación tutelar36.

\section{REFERÊNCIAS}

BARBAGELATA, Héctor-Hugo. El Derecho del Trabajo en América Latina, MTySS, Madrid, 1985.

BARBAGELATA, Héctor-Hugo. El particularismo del Derecho del Trabajo y los Derechos Humanos Laborales. FCU, Mdeo., 2009

BARBAGELATA, H-H. Derecho del Trabajo. t. I, vol. 2, 3를 ed. actualizada con la colaboración de Daniel Rivas, FCU, Mdeo., 2007.

BLANC-JOUVAN, N. II caso francese in Lavoro e Diritto. año I, N³, VII, 1987.

\section{BUENO ARÚS, F. La protección penal del trabajador en la Propuesta de}

\footnotetext{
34.- $\quad$ Bueno Arús, F., "La protección penal del trabajador en la Propuesta de Anteproyecto del nuevo Código Penal de 1983”, en AL 12 (1986), p. 579, cit. por Baylos, A. y Terradillos, J., op. cit., p. 38.

35.- $\quad$ Baylos, A. y Terradillos, J., op. cit., p. 38 y 39.

36.- $\quad$ Ghezzi, G. y Romagnoli, U., op. cit., p. 48.
} 
Anteproyecto del nuevo Código Penal de 1983.

DE BUEN, Néstor. DERECHO DEL TRABAJO, T. I, 17ª̣ ed., Ed. Porrúa, México, 2005.

DE LA CUEVA, Mario. EI Nuevo Derecho mexicano del Trabajo. 19ª edición, tomo I, Ed. Porrúa, México, 2003.

DESDENTADO BONETE, Aurelio, Prólogo a la obra de Baylos Grau, Antonio y Terradillos, Juan, Derecho Penal del Trabajo, Ed. Trotta, Madrid, 1990

DEVEALI, Mario L. La integración del Derecho del Trabajo. ILADTSS, Santa Fe, 1969.

ERMIDA URIARTE, Óscar. Las relaciones de trabajo en América Latina, Colección Crítica \& Comunicación. №2, OIT, Lima, 1991.

JAVILLIER, Jean-Claude. Manuel de Droit du Travail. cit., p. 327 y 328; De Buen, N., op. cit., p. 127 y 615; Mascaro Nascimento, Amauri, Iniciação ao Direito do Trabalho, 28ª ed., LTR, São Paulo, 2002.

KELSEN, H. Teoría pura del Derecho. Eudeba, Bs. As., 1960, p. 142. Carnelutti, Francisco, Teoría General del Derecho, Ed. Revista de Derecho Privado, Madrid, 1941.

NINO, Carlos. Introducción al análisis del derecho. $2^{\underline{a}}$ ed. ampliada y revisada, $12^{\underline{a}}$ reimpresión, Ed. Astrea, Bs. As., 2003, p. 4.

OLSZAK, N. Histoire du Droit du Travail, Histoire du Droit du Travail, ed. Económica, París, 2011.

PLÁ RODRÍGUEZ, Américo. El Derecho del Trabajo en América Latina. Sus crisis y sus perspectivas., in rev. Derecho Laboral, T. XXI, N 110, abril-junio 1978. 
PERA, Giuseppe. Diritto del Lavoro. 5a ed., Cedam, Milán, 1995, p. 607 y ss.; Ghezzi, Giorgio, Romagnoli, Umberto, II diritto sindacale, 2ª ed., Zanichelli, Bologna, 1987.

VALIDEZ, H. Eficacia del derecho. Ed. Astrea, Bs. As., 2005.

VÁZQUEZ VIALARD, Antonio y Navarro, Marcelo Julio, Policía del Trabajo, Ed. Astrea, Bs. As., 1990. 